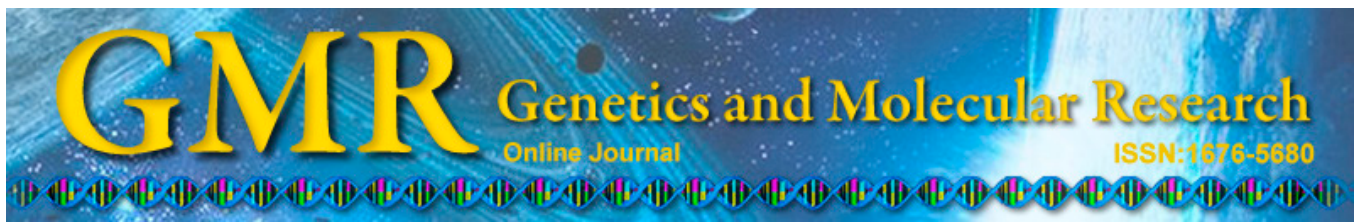

\title{
$X P G$ polymorphisms are associated with prognosis of advanced non-small cell lung cancer treated with platinum-based doublet chemotherapy
}

\author{
H.Z. Zou and Y.Q. Zhao \\ Department of Medical Oncology, \\ Affiliated Cancer Hospital of Zhengzhou University, Zhengzhou, Henan, China \\ Corresponding author: Y.Q. Zhao \\ E-mail: zhaoyanqiu6699@163.com
}

Genet. Mol. Res. 14 (1): 500-506 (2015)

Received November 19, 2013

Accepted October 28, 2014

Published January 26, 2015

DOI http://dx.doi.org/10.4238/2015.January.26.3

\begin{abstract}
We conducted a cohort study to investigate whether 3 potential single nucleotide polymorphisms (SNPs) in the xeroderma pigmentosum complementation group $\mathrm{G}(X P G)$ gene could predict the survival of advanced non-small cell lung cancer (NSCLC) patients treated with platinum-based doublet chemotherapy. We enrolled 262 patients with histologically confirmed NSCLC between November 2007 and December 2008 in this study. The 3 SNPs (rs2296147T $>$ C, rs $2094258 \mathrm{C}>\mathrm{T}$, and $\mathrm{rs} 873601 \mathrm{G}>\mathrm{A}$ ) were genotyped using polymerase chain reaction-restriction fragment length polymorphism analysis. Older age, Eastern Cooperative Oncology Group performance score $\geq 2$ and higher disease stage were associated with shorter survival. In the Cox proportional hazard model, patients carrying the rs2296147 TT genotype and the $\mathrm{T}$ allele had a significantly reduced risk of developing progressive disease or dying from NSCLC. The HRs $(95 \% \mathrm{CI})$ were $0.31(0.13-0.73)$ and $0.44(0.24-0.83)$ for progression-free survival and $0.32(0.14-0.71)$ and $0.54(0.32-0.98)$ for overall survival, respectively.
\end{abstract}


Moreover, advanced NSCLC patients carrying the rs2094258 GG and the $\mathrm{G}$ allele had a significantly decreased risk of developing progressive disease. The HRs $(95 \% \mathrm{CI})$ for the rs $2094258 \mathrm{GG}$ genotype and the $\mathrm{G}$ allele were $0.35(0.16-0.80)$ and $0.45(0.23-0.86)$ for overall survival, respectively. We suggest that the rs2296147 and rs2094258 polymorphisms could be used as surrogate markers, leading to individualization of NSCLC treatment strategies.

Key words: Non-small cell lung cancer; Overall survival; Progression; Xeroderma pigmentosum group $\mathrm{G}$

\section{INTRODUCTION}

Lung cancer is the most common cause of death from malignant disease worldwide, and about $80 \%$ of lung cancer cases are non-small cell lung cancer (NSCLC) (IARC, 2008). More than $70 \%$ of NSCLC patients have locally advanced or metastatic disease at the time of diagnosis due to a lack of effective diagnostic methods for early-stage disease (IARC, 2008). Therefore, most of these cancer patients are not diagnosed until after the ideal time for them to undergo operations that could prolong their lives. The reported 5-year survival rate for NSCLC is less than 15\%, and NSCLC has reportedly been the most fatal cancer in China for the last 10 years (Jemal et al., 2002).

NSCLC is the predominant form of lung cancer and the third most common cause of cancer-related death worldwide (IARC, 2008). Even with advances in treatment, $70 \%$ of patients have metastatic disease after treatment, and the 5-year survival rate of NSCLC patients is still less than $15 \%$ (Molina et al., 2008). In China, NSCLC has become the leading cause of death over the past decade (IARC, 2008).

Platinum-based doublet chemotherapy with agents such as cisplatin and carboplatin has become the most frequently used chemotherapy for NSCLC. This strategy has improved the overall survival of NSCLC patients; however, the response rate is estimated to be around $20 \%$ (Jemal et al., 2002; Tahara et al., 2009). Moreover, patients with tumors of the same stage and histological type responded differently to chemotherapy, suggesting that molecular mechanisms may play a role in the efficacy of chemotherapeutic agents in NSCLC.

Platinum compounds form platinum DNA adducts, which cause interstrand crosslinking and bulky distortion of DNA, subsequently inhibiting DNA replication (Johnson et al., 2001). DNA adducts reportedly play a role in clinical outcomes, response to chemotherapy, and cancer survival (Jordan and Carmo-Fonseca, 2000; van de Vaart et al., 2000). Many mechanisms are involved in repair of DNA damage, including nucleotide excision repair (NER), base excision repair, DNA mismatch repair, and double-strand break repair pathways. Of these 4 pathways, NER is responsible for repairing platinum-DNA adducts. NER involves the cooperation of about 20 enzymes that remove and restore the segment of DNA containing a bulky adduct (Cai et al., 2012). Many studies have reported that polymorphisms in NER pathway genes can alter the efficiency of DNA repair, influencing treatment response and cancer survival (Karahalil et al., 2012; Kim et al., 2013).

The xeroderma pigmentosum complementation group $\mathrm{G}(X P G)$ gene, also known as $E R C C 5$, is an indispensable component of NER (Clarkson, 2003). XPG is involved in making a dual incision at both the 3 '- and 5'-sites of the lesion, allowing the excision of damaged oligo- 
mers 22 to 32 nucleotides long (Friedberg, 2003). Previous studies have reported that single nucleotide polymorphisms (SNPs) in $X P G$ have an important role in prognosis of various cancers (Chang et al., 2008; Bartolucci et al., 2009; Sakano et al., 2010; Fleming et al., 2012). However, few studies have examined the association of SNPs in XPG with chemotherapy response and prognosis in advanced NSCLC patients. Therefore, we conducted a cohort study to investigate whether 3 potential SNPs in $X P G$ could predict survival in advanced NSCLC patients treated with platinum-based doublet chemotherapy.

\section{MATERIAL AND METHODS}

\section{Subjects}

This study included 262 patients with histologically confirmed NSCLC between November 2007 and December 2008. All patients were recruited from the Affiliated Cancer Hospital of Zhengzhou University. Patients were excluded if they previously received radiotherapy or chemotherapy, or if they had symptomatic brain metastases, spinal cord compression, or uncontrolled massive pleural effusion. At the end, 246 patients agreed to participate in this study, giving a participation rate of $93.9 \%$. All NSCLC patients were treated with platinumbased doublet chemotherapy. The histology and TNM stage of NSCLC tumors were based on World Health Organization criteria.

\section{Treatment}

The platinum-based doublet chemotherapy regimens were $25 \mathrm{mg} / \mathrm{m}^{2}$ vinorelbine on day 1 and day 8 or $1000 \mathrm{mg} / \mathrm{m}^{2}$ gemcitabine plus $75 \mathrm{mg} / \mathrm{m}^{2}$ cisplatin or carboplatin on day 1. The platinum-based doublet chemotherapy regimens were repeated every 3 weeks for a maximum of 6 cycles. Doses of cytotoxic agents were reduced by $25 \%$ for patients who experienced grade 3 non-hematologic toxicities and grade 4 hematologic toxicities. Chemotherapy treatment ceased when patients experienced progressive disease or unacceptable toxicities. Demographic and clinical information was collected for all patients from medical records. All patients were followed-up every month by telephone until death or the end of the study.

Progression-free survival (PFS) was calculated as the time from the date of chemotherapy initiation to the time of diagnosis of progressive disease by chest radiography and computed tomography. Overall survival (OS) was calculated as the time from the date of chemotherapy initiation to the date of death or the last clinical follow-up.

\section{SNP selection and genotyping}

All patients were asked to provide $5 \mathrm{~mL}$ venous blood, and genomic DNA was isolated using a QiagenBloodKit(Qiagen, Chatsworth, CA, USA)according tomanufacturerinstructions. Three potential SNPs (rs2296147T $>$ C, rs $2094258 \mathrm{C}>$ T and $\mathrm{rs} 873601 \mathrm{G}>\mathrm{A}$ ) were selected from the National Center for Biotechnology Information SNP database (dbSNP, http://www.ncbi. nlm.nih.gov/) and SNPinfo (http://snpinfo.niehs.nih.gov/). The 3 SNPs were chosen based on the criteria that they occurred at 2 ends of the $X P G$ gene, had a minor allele frequency $>5 \%$, and influenced the activity of microRNA binding sites. Probes and primers for rs $2296147 \mathrm{~T}>\mathrm{C}$, rs2094258C $>$ T, and rs873601G $>$ A were designed by the Primer 5.0 software(PREMIER Biosoft, 
Palo Alto, CA, USA) (rs2296147T>C: forward 5'-AGCTGTCACCGCCTCCC-3' and reverse 5'-CGGCCATTCTCTGGACC-3'; rs2094258C > T: forward 5'-AGCCTCGCCTTTGCCGAT-3' and reverse 5'-CTTCTGACCCATGCCCACC-3'; rs873601G $>$ A: forward 5'-CTGGTATG AGCCCATCTA-3' and reverse 5'-AGTGACAAGCCTGTAGCC-3'). Polymerase chain reaction (PCR)-restriction fragment length polymorphism analysis was used to genotype specimens for the 3 SNPs. PCR was performed in $30-\mu \mathrm{L}$ reaction solution containing $25 \mathrm{mM}$ $\mathrm{MgCl}_{2}, 2 \mathrm{mM} 4 \mathrm{X} \mathrm{dNTP}, 20 \mu \mathrm{M}$ primers, and $5 \mathrm{U} / \mu \mathrm{L}$ Taq DNA. The PCR started at $94^{\circ} \mathrm{C}$ for 5 min, denatured at $94^{\circ} \mathrm{C}$ for $45 \mathrm{~s}$, annealed at $62^{\circ} \mathrm{C}$ for $60 \mathrm{~s}$, and extended at $72^{\circ} \mathrm{C}$ for $60 \mathrm{~s}$, with a final extension at $72^{\circ} \mathrm{C}$ for $10 \mathrm{~min}$.

\section{Statistical analysis}

All statistical analyses were performed using the SPSS statistical package, version 11.0 (SPSS Inc., Chicago, IL, USA) for Windows ${ }^{\circledR}$. Continuous and categorical variables are reported as means \pm SD and N (\%) of study participants, respectively. Comparisons between patients and control subjects were made using the Student $t$-test and the chi-square test. The survival distributions were assessed using the Kaplan-Meier method and a log-rank test. HRs and their CIs were used to analyze the association of the SNPs (rs2296147T $>$ C, rs $2094258 \mathrm{C}>\mathrm{T}$, and $\mathrm{rs} 873601 \mathrm{G}>\mathrm{A}$ ) with survival time using a multivariate Cox proportional hazard model. All tests were two-sided and $\mathrm{P}<0.05$ was considered to be significant.

\section{RESULTS}

Of the 246 patients in this study, 184 presented progressive disease and 165 died during the follow-up period that lasted until December 2012. The follow-up period for all patients ranged from 2 months to 60 months. The patients had a median age of 64.3 years (range, 32-76 years), and $69.11 \%$ were males. Shorter survival was associated with older age, Eastern Cooperative Oncology Group performance score $\geq 2$, and higher disease stage $(\mathrm{P}<0.05$; Table 1$)$.

\section{Table 1. Demographic and clinical characteristics of non-small cell lung cancer patients.}

\begin{tabular}{|c|c|c|c|c|c|c|}
\hline Characteristics & Patients $(\mathrm{N}=246)$ & $\%$ & Death & $\%$ & 5 -year survival rate (\%) & P value \\
\hline Median age (years) & $64.3(31.7-76.1)$ & & & & & \\
\hline$<60$ & 117 & 47.56 & 69 & 41.82 & 41.03 & \\
\hline$\geq 60$ & 129 & 52.44 & 96 & 58.18 & 25.58 & 0.01 \\
\hline \multicolumn{7}{|l|}{ Gender } \\
\hline Female & 76 & 30.89 & 47 & 28.48 & 38.16 & \\
\hline Male & 170 & 69.11 & 118 & 71.52 & 30.59 & 0.24 \\
\hline \multicolumn{7}{|l|}{ Smoking status } \\
\hline Non-smokers & 124 & 50.41 & 85 & 51.52 & 31.45 & \\
\hline Smokers & 122 & 49.59 & 80 & 48.48 & 34.43 & 0.62 \\
\hline \multicolumn{7}{|l|}{ ECOG performance status } \\
\hline $0-1$ & 207 & 84.15 & 133 & 80.61 & 35.75 & \\
\hline$\geq 2$ & 39 & 15.85 & 32 & 19.39 & 17.95 & 0.32 \\
\hline \multicolumn{7}{|l|}{ Histology } \\
\hline Adenocarcinoma & 149 & 60.57 & 106 & 64.24 & 28.86 & \\
\hline Squamous cell carcinoma & 97 & 39.43 & 59 & 35.76 & 39.18 & 0.09 \\
\hline \multicolumn{7}{|l|}{ Disease stage } \\
\hline III $(\mathrm{A} / \mathrm{B})$ & 58 & 23.58 & 32 & 19.39 & 44.83 & \\
\hline IV & 188 & 76.42 & 133 & 80.61 & 29.26 & 0.027 \\
\hline
\end{tabular}

$\mathrm{ECOG}=$ Eastern Cooperative Oncology Group. 
In our study, patients carrying the rs2296147 TT genotype (PFS, 23.5 months; OS, 29.4 months) and the T allele (PFS, 21.4 months; OS, 27.4 months) had significantly longer PFS and OS compared to patients with the CC genotype (PFS, 17.8 months; OS, 24.6 months) (Table 2). Similarly, patients with rs 2094258 GG and the G allele had significantly longer PFS and OS when the rs2094258 AA genotype was used as a reference. In the Cox proportional hazard model, patients carrying the rs2296147 TT genotype and the T allele had a significantly lower risk of developing progressive disease or dying from NSCLC; the HRs $(95 \% \mathrm{CI})$ were $0.31(0.13-0.73)$ and $0.44(0.24-0.83)$ for PFS and $0.32(0.14-0.71)$ and $0.54(0.32-0.98)$ for OS, respectively. Moreover, advanced NSCLC patients carrying the rs2094258 GG genotype had a significantly decreased risk of development of progressive disease, with an HR $(95 \%$ CI) of $0.41(0.17-0.97)$ for PFS. The HRs $(95 \% \mathrm{CI})$ for the rs $2094258 \mathrm{GG}$ genotype and the G allele were $0.35(0.16-0.80)$ and $0.45(0.23-0.86)$ for OS, respectively.

Table 2. Univariate analysis of XPG in relation to PFS and OS.

\begin{tabular}{|c|c|c|c|c|c|c|c|c|c|c|c|c|}
\hline \multirow[t]{2}{*}{ Gene } & \multirow[t]{2}{*}{ Cases } & \multirow[t]{2}{*}{$\%$} & \multicolumn{5}{|c|}{ PFS } & \multicolumn{5}{|c|}{ OS } \\
\hline & & & $\begin{array}{c}\text { Events } \\
(\mathrm{N}=184)\end{array}$ & $\%$ & $\begin{array}{l}\text { Median } \\
\text { (months) }\end{array}$ & $\operatorname{HR}(95 \% \mathrm{CI})^{1}$ & $\mathrm{P}$ value & $\begin{array}{c}\text { Events } \\
(\mathrm{N}=165)\end{array}$ & $\%$ & $\begin{array}{l}\text { Median } \\
\text { (months) }\end{array}$ & HR $(95 \% \mathrm{CI})^{1}$ & $P$ value \\
\hline \multicolumn{13}{|l|}{ rs2296147 } \\
\hline $\mathrm{CC}$ & 132 & 53.66 & 108 & 58.70 & 17.8 & 1 & - & 96 & 58.2 & 24.6 & 1.0 (Ref.) & - \\
\hline $\mathrm{CT}$ & 76 & 30.89 & 54 & 29.35 & 19.2 & $0.55(0.27-1.12)$ & 0.07 & 50 & 30.3 & 25.9 & $0.89(0.46-1.76)$ & 0.26 \\
\hline TT & 38 & 15.45 & 22 & 11.96 & 23.5 & $0.31(0.13-0.73)$ & 0.002 & 19 & 11.5 & 29.4 & $0.32(0.14-0.71)$ & 0.004 \\
\hline $\mathrm{T}$ allele & 114 & 46.34 & 76 & 41.30 & 21.4 & $0.44(0.24-0.83)$ & 0.006 & 69 & 41.8 & 27.4 & $0.54(0.32-0.98)$ & 0.04 \\
\hline \multicolumn{13}{|l|}{ rs 873601} \\
\hline AA & 99 & 40.24 & 78 & 42.39 & 17.9 & 1 & - & 72 & 43.6 & 26.1 & 1.0 (Ref.) & - \\
\hline $\mathrm{AG}$ & 114 & 46.34 & 84 & 45.65 & 18.4 & $0.75(0.38-1.49)$ & 0.38 & 75 & 45.5 & 26.3 & $0.86(0.46-1.61)$ & 0.62 \\
\hline GG & 33 & 13.41 & 22 & 11.96 & 20.6 & $0.54(0.21-1.44)$ & 0.16 & 18 & 10.9 & 27.4 & $0.50(0.21-1.22)$ & 0.08 \\
\hline G allele & 147 & 59.76 & 106 & 57.61 & 19.6 & $0.70(0.36-1.32)$ & 0.24 & 93 & 56.4 & 26.8 & $0.76(0.42-1.36)$ & 0.32 \\
\hline \multicolumn{13}{|c|}{ rs2094258 } \\
\hline AA & 82 & 33.33 & 67 & 36.41 & 16.8 & 1 & - & 64 & 38.8 & 23.9 & 1.0 (Ref.) & - \\
\hline $\mathrm{AG}$ & 110 & 44.72 & 82 & 44.57 & 18.2 & $0.66(0.30-1.40)$ & 0.24 & 71 & 43.0 & 24.7 & $0.51(0.25-1.03)$ & 0.05 \\
\hline GG & 54 & 21.95 & 35 & 19.02 & 23.1 & $0.41(0.17-0.97)$ & 0.03 & 30 & 18.2 & 30.4 & $0.35(0.16-0.80)$ & 0.006 \\
\hline $\mathrm{G}$ allele & 164 & 66.67 & 117 & 63.59 & 20.6 & $0.56(0.27-1.11)$ & 0.08 & 101 & 61.2 & 27.8 & $0.45(0.23-0.86)$ & 0.01 \\
\hline
\end{tabular}

${ }^{1}$ Adjusting for gender, age, histology, ECOG performance status, and disease stage: $\mathrm{ECOG}=$ Eastern Cooperative Oncology Group; OS = overall survival; PFS = progression-free survival; XPG $=$ xeroderma pigmentosum complementation group $\mathrm{G}$.

\section{DISCUSSION}

DNA repair is important for ensuring genome integrity and stability, and genome instability could promote cellular changes that lead to the progressive transformation of cancerous cells. Therefore, defects in genes involved in DNA repair pathways could induce carcinogenesis. $X P G$ is required to make an incision necessary for the excision of damaged oligonucleotides through cleavage on the $3^{\prime}$ side of sites of DNA damage during the NER DNA repair pathway (Friedberg, 2003). Previous studies have demonstrated that enhanced NER is associated with resistance to platinum agents, and reduced NER activity correlates with sensitivity to platinum agents. Therefore, polymorphisms in $X P G$ may affect the clinical outcomes of cancer patients treated with platinum-based chemotherapy (Kang et al., 2013). Previous evidence suggests that polymorphisms in $X P G$ affect the response to platinum-based chemotherapy and clinical outcomes of various cancers including osteosarcoma, melanoma, bladder cancer, and gastric cancer (Canbay et al., 2010; Sakano et al., 2010; Schrama et al., 2011; Biason 
et al., 2012). Therefore, we investigated whether 3 common SNPs in $X P G$ were related to the prognosis of patients with advanced NSCLC treated with platinum-based chemotherapy. In our study, we found that polymorphisms in rs2296147 and rs2094258 were significantly associated with the prognosis of advanced NSCLC patients. However, the rs 873601 genotype was not significantly associated with PFS and OS in advanced NSCLC patients treated with platinum-based chemotherapy. Our study showed that down-regulation of rs 2296147 and rs 2094258 was associated with reduced risk of progressive disease and death from advanced NSCLC, which suggested that down-regulation of rs2296147 and rs2094258 might alter the ability of cells to repair DNA damage caused by chemotherapy.

Several studies have reported an association between $X P G$ polymorphisms and clinical outcomes of advanced NSCLC patients, but the results are inconsistent (Zienolddiny et al., 2006; Bartolucci et al., 2009; Sun et al., 2009; Butkiewicz et al., 2011; Zhang et al., 2012). Zhang et al. (2012) conducted a study in China to investigate the association between 5 SNPs in $X P G$ and the prognosis of NSCLC patients. They reported that rs $1047768 \mathrm{C} / \mathrm{T}$ and rs 2296147 $\mathrm{C} / \mathrm{T}$ correlated with clinical outcomes of NSCLC patients treated with platinum-based chemotherapy. Another study in Poland reported no association between XPG polymorphisms and NSCLC outcomes (Butkiewicz et al., 2011). Sun et al. (2009) reported a significant association between an rs1047768 polymorphism and the prognosis of NSCLC patients. Our study indicated that polymorphisms in rs2296147 and rs2094258 were significantly associated with a 0.31 - to 0.55 -fold risk of developing progressive disease and dying from NSCLC. The different results seen by these various studies might be explained by differences in patient backgrounds, control selection, and sample size, among others. Therefore, studies with large sample sizes are needed to validate these associations.

Our study had several limitations that should be considered. First, all the NSCLC patients were recruited from a single hospital, and these cases may not be representative of patients from other populations. In addition, there may be a selection bias and information bias. However, potential bias can be minimized in the final analysis by adjusting for gender, age, smoking status, ECOG performance score, and disease stage, which could minimize the selection bias. Second, we investigated only 3 common SNPs in $X P G$, and other SNPs may interact with these 3 common SNPs. Third, our study had a relatively small sample size, which reduced the statistical power to detect differences between groups. Therefore, future welldesigned studies with large sample sizes are needed to confirm the association between XPG polymorphisms and the prognosis of NSCLC patients.

In summary, our study provides statistical evidence that polymorphisms in rs 2296147 and rs2094258 in the XPG gene are associated with reduced risk of developing progressive diseases and dying in advanced NSCLC patients treated with platinum-based chemotherapy. Therefore, we suggest that rs2296147 and rs2094258 polymorphisms can be used as surrogate markers, leading us toward individualization of NSCLC treatment strategies.

\section{REFERENCES}

Bartolucci R, Wei J, Sanchez JJ, Perez-Roca L, et al. (2009). XPG mRNA expression levels modulate prognosis in resected non-small-cell lung cancer in conjunction with BRCA1 and ERCC1 expression. Clin. Lung Cancer 10: 47-52.

Biason P, Hattinger CM, Innocenti F, Talamini R, et al. (2012). Nucleotide excision repair gene variants and association with survival in osteosarcoma patients treated with neoadjuvant chemotherapy. Pharmacogenomics J. 12: 476-843.

Butkiewicz D, Rusin M, Sikora B, Lach A, et al. (2011). An association between DNA repair gene polymorphisms and survival in patients with resected non-small cell lung cancer. Mol. Biol. Rep. 38: 5231-5241. 
Cai Y, Geacintov NE and Broyde S (2012). Nucleotide excision repair efficiencies of bulky carcinogen-DNA adducts are governed by a balance between stabilizing and destabilizing interactions. Biochemistry 51: 1486-1499.

Canbay E, Agachan B, Gulluoglu M, Isbir T, et al. (2010). Possible associations of APE1 polymorphism with susceptibility and HOGG1 polymorphism with prognosis in gastric cancer. Anticancer Res. 30: 1359-1364.

Chang JS, Wrensch MR, Hansen HM, Sison JD, et al. (2008). Nucleotide excision repair genes and risk of lung cancer among San Francisco Bay Area Latinos and African Americans. Int. J. Cancer 123: 2095-2104.

Clarkson SG (2003). The XPG story. Biochimie 85: 1113-1121.

Fleming ND, Agadjanian H, Nassanian H, Miller CW, et al. (2012). Xeroderma pigmentosum complementation group C single-nucleotide polymorphisms in the nucleotide excision repair pathway correlate with prolonged progressionfree survival in advanced ovarian cancer. Cancer 118: 689-697.

Friedberg EC (2003). DNA damage and repair. Nature 421: 436-440.

International Agency for Research on Cancer (IARC) (2008). Lung cancer incidence, mortality and prevalence worldwide in 2008. Available at [http://globocan.iarc.fr/factsheet.asp].

Jemal A, Thomas A, Murray T and Thun M (2002). Cancer statistics, 2002. CA: Cancer J. Clin. 52: 23-47.

Johnson SW, Stevenson JP and O'Dwyer PJ (2001). Cisplatin and its analogues. In: Cancer: principles and practice of oncology, 6th edn. (DeVita VT, Hellman S and Rosenberg SA, eds.). Lippincott Williams and Wilkins, Philadelphia, 376-388.

Jordan P and Carmo-Fonseca M (2000). Molecular mechanisms involved in cisplatin cytotoxicity. Cell. Mol. Life Sci. 57: 1229-1235.

Kang S, Sun HY, Zhou RM, Wang N, et al. (2013). DNA repair gene associated with clinical outcome of epithelial ovarian cancer treated with platinum-based chemotherapy. Asian Pac. J. Cancer Prev. 14: 941-946.

Karahalil B, Bohr VA and Wilson DM 3rd (2012). Impact of DNA polymorphisms in key DNA base excision repair proteins on cancer risk. Hum. Exp. Toxicol. 31: 981-1005.

Kim KY, Han W, Noh DY, Kang D, et al. (2013). Impact of genetic polymorphisms in base excision repair genes on the risk of breast cancer in a Korean population. Gene 532: 192-196.

Molina JR, Yang P, Cassivi SD, Schild SE, et al. (2008). Non-small cell lung cancer: epidemiology, risk factors, treatment, and survivorship. Mayo Clin. Proc. 83: 584-594.

Sakano S, Hinoda Y, Sasaki M, Wada T, et al. (2010). Nucleotide excision repair gene polymorphisms may predict acute toxicity in patients treated with chemoradiotherapy for bladder cancer. Pharmacogenomics 11: 1377-1387.

Schrama D, Scherer D, Schneider M, Zapatka M, et al. (2011). ERCC5 p.Asp1104His and ERCC2 p.Lys751Gln polymorphisms are independent prognostic factors for the clinical course of melanoma. J. Invest. Dermatol. 131: 1280-1290.

Sun X, Li F, Sun N, Shukui Q, et al. (2009). Polymorphisms in XRCC1 and XPG and response to platinum-based chemotherapy in advanced non-small cell lung cancer patients. Lung Cancer 65: 230-236.

Tahara E, Yasui W, Ito H, Harris CC, et al. (2009). Recent progress in carcinogenesis, progression and therapy of lung cancer: the 19th Hiroshima Cancer Seminar: the 3rd Three Universities' Consortium International Symposium. Jpn. J. Clin. Oncol. 40: 702-708.

van de Vaart PJ, Belderbos J, de Jong D, Sneeuw KC, et al. (2000). DNA-adduct levels as a predictor of outcome for NSCLC patients receiving daily cisplatin and radiotherapy. Int. J. Cancer 89: 160-166.

Zhang L, Gao G, Li X, Ren S, et al. (2012). Association between single nucleotide polymorphisms (SNPs) and toxicity of advanced non-small-cell lung cancer patients treated with chemotherapy. PLoS One 7: e48350.

Zienolddiny S, Campa D, Lind H, Ryberg D, et al (2006). Polymorphisms of DNA repair genes and risk of non-small cell lung cancer. Carcinogenesis 27: 560-567. 